\title{
Alcances para una respuesta jurídica integral al comercio ilegal de oro")
}

\section{Approaches for a comprehensive regulatory response to illegal gold commerce}

\author{
Vanessa Sofía Valverde Luna $a^{(*)}$ \\ Universidad de Lima \\ Diego Alonso Collantes Añaños ${ }^{(* *)}$ \\ Pontificia Universidad Católica del Perú
}

\begin{abstract}
Resumen: El presente trabajo apunta a evaluar el funcionamiento y las limitaciones de algunas de las herramientas jurídicas que el Estado peruano ha planteado como parte de su respuesta normativa frente al grave fenómeno de la minería ilegal, forma organizada de criminalidad cuyas ganancias ilícitas han superado en los últimos años a las del tráfico ilícito de drogas. Con tal finalidad, se han propuesto dos ejes de análisis con incidencia en la comercialización del oro ilegal: (i) las herramientas penales, que específicamente comprenden los delitos de minería ilegal, comercio clandestino y lavado de activos; y (ii) las herramientas administrativas, compuestas por los Decretos Legislativos No. 1103 y 1107, los Decretos Supremos No. 012-2012-EM y No. 17-2009-MTC, entre otros. Los autores han advertido diversos errores de política legislativa en estos elementos e implementan recomendaciones para incrementar la eficacia global de la regulación.
\end{abstract}

Palabras Clave: Minería llegal - Comercialización de Oro - Comercio Clandestino - Lavado de Activos - Rutas Fiscales - Transporte Terrestre de Valores - Adquirente de Oro - Formalización de la Pequeña Minería y Minería Artesanal

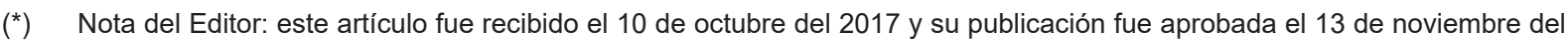
2017.

${ }^{* *}$ Magíster en Derecho Penal por la Universidad Pompeu Fabra y Universidad de Barcelona. Asociada Senior del área penal del Estudio Benites \& Ugaz. Correo electrónico: vvalverde@bvu.pe

$\left.{ }^{(* *}\right)$ Bachiller de la Facultad de Derecho de la Pontificia Universidad Católica del Perú. Adjunto de Docencia del Seminario en Integración de Teoría General del Derecho y asistente en el Estudio Benites \& Ugaz. Correo electrónico: dcollantes@bvu.pe 


\section{Alcances para una respuesta jurídica integral al comercio ilegal de oro Approaches for a comprehensive regulatory response to illegal gold commerce}

\begin{abstract}
This paper pretends to analyze the functioning and the limitations of some legal tools that the Peruvian state has posed as a part of his normative answer to the grave phenomenon of illegal gold mining, organized form of criminality whose utilities have surpassed the ones of drug trafficking. With this purpose, two axes of analysis has been proposed with incidence upon the illegal commercialization of gold: (i) the criminal tools, which specifically involve the crimes of illegal mining, clandestine commerce and money laundering; and (ii) the administrative tools, which involve the Legislative Decrees $N^{\circ} 1103$ and 1107, the Supreme Decrees $N^{\circ} 012-2012-E M$ and $N^{\circ} 17-2009-M T C$, among others. The authors have noticed several legislative policy errors in these elements and therefore implement recommendations to increase the global effectiveness of the regulation.
\end{abstract}

Keywords: Illegal Mining - Gold Commercialization - Clandestine Commerce - Money Laundering - Checkpoint Routes - Transport of Values - Gold Acquiring - Formalizing of the Minor Mining and Artisanal and small scale mining.

Sumario: 1. Introducción_2. La minería ilegal_2.1. Escala y consecuencias de la minería ilegal. Respuesta estatal mixta_2.2. La minería ilegal e informal en nuestro ordenamiento jurídico: marco legal_3. Principales herramientas jurídicas contra la minería ilegal_3.1. Herramientas penales_3.1.1. El delito de minería ilegal_3.1.2. El delito de comercio clandestino_3.1.3. El delito de lavado de activos: el tipo básico_3.1.3.1 Tratamiento jurisprudencial del lavado de activos_3.2. Herramientas administrativas_3.2.1. Las rutas fiscales_3.2.2. El Reglamento Nacional de Administración de Transporte y las empresas transportistas de valores_3.2.3. Responsabilidad del adquirente de productos mineros_3.2.4. Breves notas sobre el proceso de formalización_4. Sistema complejo: dinámica y actores al margen de la legalidad en la ruta de comercialización del mineral aurífero_5. Conclusiones.

\section{Introducción}

La criminalidad organizada conlleva un especial desafío para su efectiva investigación y sanción debido a la escala y complejidad de sus múltiples actividades, cada una de las cuales posee sus propias características criminológicas, lo que además hace que no exista una definición común ${ }^{(1)}$ que abarque todos los ámbitos en los que ésta se despliega ${ }^{(2)(3)}$. De lo anterior se sigue que un estudio o política que aborde el crimen organizado, en cualquiera de sus muchas formas, requiere necesariamente la comprensión de la lógica de la actividad específica en la que éste se desarrolla. El

(1) Al respecto, Letizia Paoli y Tom Vander Beken precisan lo siguiente: "Si bien el término crimen organizado aún tiene un fuerte poder evocador, lo que indudablemente explica su éxito en el plano de lo político, los muchos actores criminales y actividades que han sido subsumidos bajo esta etiqueta han hecho de él un vago concepto que no puede ser usado, sin especificación, como base para análisis empíricos, construcción de teorías o formulación de políticas." (Traducción libre de los autores). Véase Letizia Paoli, "Organized Crime: A Contested Concept," ed. The Oxford Handbook of Organized Crime (New York: Oxford University Press, 2014), 13.

(2) Se han propuesto cuatro interesantes razones para explicar el vacío normativo que existe en el derecho penal con relación a dicho concepto, a saber: Primero, que el concepto de criminalidad organizada ha ido calando en el ideario colectivo a partir de las experiencias norteamericanas exportadas a nivel mundial. Segundo, que la noción de criminalidad organizada se ha construido históricamente desde la criminología, de modo que su extrapolación al derecho penal como saber normativo no es sencillo. Tercero, el universo de significados que denota la noción de criminalidad organizada es heterogéneo, complejo y variable, por lo que difícilmente encaja en el modelo de la norma penal. Cuarto, el derecho penal ha sido construido sobre la base de un comportamiento de autor individual y la criminalidad organizada supone un comportamiento de grupo, de organización. Véase Felipe Villavicencio Terreros, "Criminalidad Organizada y el Delito de Asesinato," en Laura Rodríguez, directora; Fidel Mendoza, coord. Ley contra el Crimen Organizado (Ley No. 30077) Aspectos Sustantivos, Procesales y de Ejecución Penal (Lima: Instituto Pacífico, 2016), 113.

(3) Desde luego, ello no ha impedido que se enumeren sus características más básicas (pluralidad de agentes, permanencia en el tiempo, perpetración de graves delitos, entre otras) a través de instrumentos internacionales como la Convención de Naciones Unidas contra la Delincuencia Organizada Transnacional o, más recientemente y en el plano local, con la Ley 30077. 


\section{Vanessa Sofía Valverde Luna y Diego Alonso Collantes Añaños}

plano normativo, si pretende ser eficaz en su aplicación, ha de partir del conocimiento de las dinámicas económicas y sociales sobre las que opera la delincuencia organizada.

Por otro lado, el crimen organizado en el siglo veintiuno posee un conjunto de particularidades que se superponen a un ámbito ya complejo; nos referimos a los atributos cada vez más consolidados de la globalización, que implican, entre otras cosas, la disminución de autonomía de los Estados y, por tanto, la pérdida de capacidad para proteger a sus ciudadanos frente a las consecuencias de procesos que se originan fuera de sus fronteras, pero cuya intensidad viene dada por la interdependencia económica (Habermas 2001).

La doctrina penal no ha sido ajena a este fenómeno; se ha planteado que la delincuencia de la globalización es por definición organizada y se trata de la delincuencia de los poderosos, que deja de lado la idea de delincuencia como fenómeno marginal, para caracterizarse por la magnitud de sus efectos económicos, políticos y sociales, así como por su capacidad para corromper funcionarios y gobernantes (Silva Sánchez 2011: 90-1). Esta delincuencia de los poderosos se diferencia de la delincuencia tradicional, además, por tener una regulación legal insuficientemente asentada, cuya dogmática se halla todavía en elaboración (Silva Sánchez 2011: 85-6).

La convergencia de la criminalidad organizada, caracterizada por sus métodos sofisticados y su gran envergadura, con la sociedad de la globalización y sus redes económicas sin fronteras, constituye un problema que ya se había advertido desde la teoría hace por lo menos un par de décadas, pero cuya complejidad práctica recién se está materializando como un gran desafío para los Estados, especialmente difícil para aquellos que, como el Perú, se encuentran las vías de desarrollo; pues la suma de (i) regulación defectuosa o insuficiente, (ii) institucionalidad precaria; y, (iii) falta de enforcement de la ley, agravan una situación de por sí delicada.

Fue en este contexto que se insertó en el Perú una actividad organizada, hasta entonces poco conocida, de enorme magnitud económica, con impactos devastadores sobre la población local y el medio ambiente, así como con conexiones internacionales: la minería ilegal. En muy poco tiempo, esta actividad, cuyo objetivo primordial es la extracción de oro, ocupó, sin limitarse a tales, grandes zonas de la Amazonía peruana, particularmente en el departamento de Madre de
Dios, donde sistemáticamente ha causado deforestación y contaminación, ha desplazado población local y ha generado redes de explotación sexual en áreas que pasaron a convertirse en los márgenes de la república.

La reacción punitiva estatal llegó tardíamente en el año 2012, a través del Decreto Legislativo No. 1102, que tipificó por primera vez en la historia del Perú el delito de minería ilegal, y con la publicación del Decreto Legislativo No. 1106, que consideró la minería ilegal como delito fuente de otro delito característico de la moderna criminalidad organizada, el lavado de activos.

Actualmente, la minería ilegal es parte del crimen organizado y continúa generando los impactos devastadores descritos; mientras las toneladas de oro extraído encuentran poderosos compradores en el mercado formal internacional, que con la intervención de actores locales y por medio de esquemas comerciales, logran otorgar apariencia de legalidad a una actividad que, a estas alturas, tiene que tratarse como un asunto de primer orden para la seguridad y el bienestar nacional.

No obstante, no se debe perder de vista que, a diferencia del narcotráfico, el producto de la minería ilegal, el oro, es un bien per se perfectamente lícito dentro del mercado, por lo que una política legislativa adecuada debe combatir tanto la actividad minera ilegal en sí misma, como todos aquellos elementos que facilitan la comercialización, a nivel local e internacional, del oro extraído. En esa línea, es indispensable alcanzar un punto de equilibrio, donde se genere la mayor cantidad de costos de transacción para la comercialización de oro ilegal, con la menor cantidad de perjuicios para quienes lo hacen lícitamente.

Un sistema de justicia eficaz contra la minería ilegal y el comercio ilegal de oro necesita 


\section{Alcances para una respuesta jurídica integral al comercio ilegal de oro Approaches for a comprehensive regulatory response to illegal gold commerce}

ir más allá de la interpretación exegética del texto de las normas penales y administrativas, requiere de legisladores y operadores con un mínimo de conocimiento sobre la cadena de comercialización de una actividad que, en el marco de la globalización, involucra incluso a empresas internacionales.

Creemos que así pueden corregirse los defectos actuales en la regulación sobre el transporte y el comercio ilegal del oro, mientras se consigue sancionar a los responsables de la devastación de la Amazonía y de la generación de perversas consecuencias colaterales. Ese es el propósito que ha motivado a los autores de esta pequeña contribución.

\section{La minería ilegal}

\subsection{Escala y consecuencias de la minería ilegal. Respuesta estatal mixta}

El Perú aún no es un país industrializado y las exportaciones de materias primas constituyen su principal fuente de ingresos. En esa realidad, la minería formal ha representado en los últimos años aproximadamente el $59 \%$ de las exportaciones totales y el $14.5 \%$ del Producto Bruto Interno (En adelante, "PBI") (Macroconsult 2012, 2); además, es fuente generadora directa e indirecta de puestos de trabajo, por lo que su rol dentro del modelo económico actual es preponderante. Así, es un hecho que, en el estado de las cosas, la minería formal, cuando se practica adecuadamente ${ }^{(4)}$, puede ser un factor hacia el desarrollo colectivo.

Debe advertirse que desde el año 2004 en adelante, el Perú experimentó un potente ciclo de crecimiento económico sobre la base del denominado boom extractivo de recursos naturales, especialmente minerales (oro y cobre), lo que trajo consigo una serie de desafíos institucionales para la república del siglo veintiuno.

Sin embargo, esta vinculación entre la minería y la economía peruana no es en absoluto novedosa; de hecho, desde 1925 hasta la actualidad, la exportación de minerales ha constituido en muchos períodos más del $50 \%$ del total de las exportaciones nacionales; y, en los últimos 20 años, la minería ha representado, en promedio, $10 \%$ del PBI hasta alcanzar un tope de $15 \%$ en el año 2006 (Dargent y otros, 2017). De este modo, Perú junto con Bolivia y Chile, es uno de los países donde las industrias extractivas representan el mayor porcentaje del PBI en América Latina (Dargent y otros, 2017).

Ahora bien, al igual que la minería es una característica de la economía peruana, también lo es la informalidad, que no es ajena a dicho sector en general. Prueba de ello, es que para el año 2012, se estimó que la extracción ilegal de oro había superado, por lo menos, las dieciocho toneladas, lo que representaba más de S/. 2200 millones de soles y, a su vez, más de $S / .500$ millones en pérdidas de recaudación tributaria(5). Igualmente, la minería ilegal e informal, cuya distinción se abordará más adelante, se encuentra presente en veintiún regiones del país y ocupa a aproximadamente cien mil trabajadores directos ${ }^{(6)}$.

(4) No deja de ser preocupante, aún desde el ámbito de la formalidad, que durante el denominado boom extractivo (2004-2014) se hayan implementado una gran cantidad de modificaciones legales orientadas a incrementar el tratamiento penal, en los delitos contra el orden público y otros, de las protestas sociales; que los niveles de conflictividad socioambiental hayan aumentado de $20 \%$ en 2005 a $68.9 \%$ del total de conflictos en 2016 y que, simultáneamente a la flexibilización, mediante Leyes y Decretos Legislativos, de los límites legales del uso de la fuerza por parte de la Policía Nacional en contextos de conflicto social, se hayan firmado 112 convenios de servicios de seguridad entre la PNP y empresas mineras, de los cuales 20 se encuentran vigentes. Saldaña Cuba, José y Jorge Portocarrero Salcedo, "La violencia de las leyes: el uso de la fuerza y la criminalización de protestas socioambientales en el Perú," Derecho PUCP 79 (2017): 311-52.

(5) Véase nota de prensa No. 158-2012 de la SUNAT, citada por Defensoría del Pueblo. Informe de Adjuntía No. 001-2013-DP/ AMASPPI.MA "Gestión del Estado Frente a la Minería Informal e llegal en el Perú. Supervisión a la implementación de los Decretos Legislativos Promulgados al amparo de la Ley No. 29815” (Lima: Defensoría del Pueblo, 2013 ), 7.

(6) Véase nota de prensa No. 158-2012 de la SUNAT, citada por Defensoría del Pueblo. 


\section{Vanessa Sofía Valverde Luna y Diego Alonso Collantes Añaños}

En esa línea, y según información generada por la Unidad de Inteligencia Financiera (En adelante, "UIF"), en el año 2014 se produjo un punto de quiebre histórico, puesto que por primera vez en términos anuales se identificó mayor dinero proveniente de una actividad ilícita distinta al narcotráfico (Poder 2015); no se trató de una simple foto, pues en el global acumulado hasta marzo del año 2015 , la minería ilegal ya había generado $\$ 4,299$ millones y el narcotráfico $\$ 5,125$ millones, pese a que la UIF comenzó a registrar esta última actividad desde el 2007 y la primera sólo desde el 2012. Las dimensiones adquiridas por esta actividad ilícita revelaron un grave y complejo desafío para el Estado.

No puede entenderse el vertiginoso auge y propagación de la minería ilegal e informal sin la relación de causalidad que esta tuvo con el alza del precio internacional del oro en el contexto de crisis económica global, en la segunda mitad de la década del 2000. Así, no es fortuito que la producción mundial de oro se haya incrementado de 2445 toneladas métricas en el año 2000 a 2770 toneladas métricas para el año 2013, lo que se explica por factores, tanto de incertidumbre en los mercados financieros globales -devaluación del dólar y del euro, por ejemplo- como de consumo personal, particularmente en China e India.

En tal escenario, el precio del oro se incrementó de \$250 dólares la onza en el año 2000 a $\$ 1300$ dólares la onza en el año 2013 (Shafiee y Topal 2010). Este incremento en la demanda mundial y el precio del oro, estimuló y potenció otras formas de actividad minera, tanto por parte de compañías multinacionales, como de mineros de pequeña escala alrededor del mundo e hizo posible la extracción de oro desde áreas donde previamente no resultaba rentable; siendo que, en América Latina, estas zonas fueron los bosques amazónicos, añadiendo así una causa adicional de deforestación (AlvarezBerríos y Aide 2015).
En el plano nacional, es ilustrativo de toda la línea de sucesos hasta aquí descrita lo que comenzó a ocurrir en el departamento de Madre de Dios entre los años 2007 y 2009, donde se desató la tercera -y más grandefiebre del oro de su historia, que a su vez desnaturalizó la pequeña minería aurífera fluvial ya existente hace décadas e hizo que, según estimaciones, para el año 2011 se convirtiera en el tercer mayor departamento productor de oro del Perú (Sociedad Peruana de Derecho Ambiental 2015).

Esta situación fue posible por la combinación de la demanda internacional de oro y la construcción en paralelo de la carretera interoceánica, que conectó zonas que eran prácticamente inaccesibles y abarató los costos de transporte de las maquinarias empleadas por la minería ilegal, la cual se consolidó en la zona, donde a la fecha ya se han deforestado miles de hectáreas que, además, han sido contaminadas con mercurio (Sociedad Peruana de Derecho Ambiental 2015) $)^{(7)}$.

La situación en las áreas donde actualmente se practica la minería ilegal e informal en el departamento de Madre de Dios se caracteriza por la escasa y muchas veces inexistente presencia del Estado. Los estudios sociales allí practicados revelan que los espacios de extracción de oro en dicho departamento son puntos de confluencia del tráfico de cocaína, contrabando diverso, prostitución y trata de personas; donde miles de trabajadores,

(7) Véase con relación a la contaminación derivada de la minería ilegal: "La minería aurífera en la Amazonía peruana representa un peligro grave, presente y latente para la salud de las personas y el ambiente en general. Todos los indicadores muestran preocupantes niveles de contaminación de agua, de los sedimentos de los ríos, de los peces y de las personas. Aunque no ha habido un plan de monitoreo articulado de estos indicadores y los estudios no son totalmente comparables, se puede apreciar que la contaminación es creciente y directamente proporcional al incremento de las actividades mineras." Brack, Antonio, José Alvarez y Víctor Sotero. Minería Aurífera en Madre de Dios y Contaminación con Mercurio - Una Bomba de Tiempo (Lima: Ministerio del Ambiente. 2011). 


\section{Alcances para una respuesta jurídica integral al comercio ilegal de oro Approaches for a comprehensive regulatory response to illegal gold commerce}

sin un único director central, han producido una cadena de economías tanto ilegales como informales de tipo migrante.

Asimismo, desde una perspectiva antropológica, se han identificado dos grandes grupos, muchas veces compuestos por menores de edad, involucrados en el circuito de la minería ilegal: los sujetos que padecen explotación laboral y los que padecen explotación sexual. Dentro del primer gran grupo dedicado a la extracción de mineral se encuentran subgrupos: aquellos que están en condiciones severas de explotación laboral; los que, estando en condiciones de explotación, son sometidos además a mecanismos de trata de personas; y otros que son sometidos a prácticas de semi esclavitud. En el grupo de quienes padecen explotación sexual se identifican a mujeres adolescentes que se han desplazado estacionalmente para ofrecer servicios sexuales en la zona, así como quienes tienen restricciones de desplazamiento, coacción por deudas y que cumplen con criterios asociados a la trata de personas (Mujica 2014).

Más aun, en el caso de la trata de personas se ha visto que ésta es dependiente de sistemas delictivos o informales paralelos de mayor capacidad económica, por lo que no es posible controlarla sin considerar, primero, la complejidad de tales sistemas y su entorno (Ministerio de Justicia y Derechos Humanos 2017). Una vez que dicha consideración sea realizada, el sistema penal deberá priorizar su aplicación efectiva en aquellos objetivos criminológicos que producen mayor impacto y daño (Ministerio de Justicia y Derechos Humanos 2017).

Creemos que la respuesta estatal regulatoria frente a la minería ilegal y sus consecuencias, que comprende ámbitos penales y administrativos, debe tomar en cuenta cinco componentes que, a decir de la literatura especializada, integran el marco de referencia de una regulación eficaz (DREAM), a saber: detección (Detecting); respuesta (Responding); aplicación (Enforcing); valoración (Assessing); modificación (Modifying) (Baldwin, Cave y Lodge 2012).

La detección es la adquisición de información del comportamiento contrario al ordenamiento; la respuesta, el desarrollo de políticas, reglas, y herramientas orientadas a tratar con el problema descubierto; el enforcement( ${ }^{(8)}$, la aplicación de las políticas, reglas, y herramientas desarrolladas; la valoración, la medición del éxito o fracaso de las actividades de enforcement; la modificación, el ajuste de herramientas y estrategias con la finalidad de mejorar el cumplimiento y la forma en que se ha abordado la conducta problemática (Baldwin, Cave y Lodge 2012). Nuestro trabajo incidirá principalmente en el análisis de los componentes de valoración (assessing) y modificación (modifiying).

En efecto, el Estado peruano ha desplegado esfuerzos para reprimir la minería ilegal a través de la creación y modificación de una serie de normas de índole tanto penal como administrativa. A título enunciativo, y sin perjuicio de su posterior desarrollo, podemos encontrar entre lo más resaltante lo siguiente.

Desde el ámbito penal, se tipificó la minería ilegal como delito autónomo y se modificó la redacción del delito de comercio clandestino; asimismo, se emitió un nuevo Decreto Legislativo para sancionar el lavado de $\operatorname{activos}^{(9)}$, donde se hizo referencia explícita a la minería ilegal como delito fuente o precedente.

Desde el ámbito administrativo, se establecieron rutas fiscales para el transporte y comercialización de insumos y bienes utilizados en la minería ilegal, así como para el producto minero en sí; se fijaron exigencias para la adquisición de oro y se inició un proceso de formalización minera.

No obstante, creemos que se requiere realizar algunas reevaluaciones y modificaciones en ambos componentes de la respuesta reguladora penal y administrativa del Estado, a fin de afrontar de manera eficaz la minería

(8) Aquí hemos preferido mantener la conjugación del idioma original, con fines de diferenciación.

(9) La cual derogó la Ley Nº 27765 - Ley Penal contra del Lavado de Activos, del año 2002. 


\section{Vanessa Sofía Valverde Luna y Diego Alonso Collantes Añaños}

ilegal y sus consecuencias. Para ello, es también necesario entender los componentes y el funcionamiento de la cadena de comercialización del mineral extraído.

\subsection{Minería ilegal e informal en nuestro ordenamiento jurídico: marco legal}

Se debe diferenciar la minería informal de la minería ilegal. Es sabido que ambas forman parte de una categoría a la que se denomina minería no formal. El primer antecedente normativo orientado a frenar la actividad minera practicada al margen de la legalidad fue la Ley No. 27651, Ley de Formalización y Promoción de la Pequeña Minería y la Minería Artesanal, del 24 de enero del 2002, a partir del cual se planteó la posibilidad de que los pequeños mineros y mineros artesanales puedan formalizarse.

Con el boom extractivo a punto de alcanzar su etapa más intensa y la minería informal en aumento se expidió el Decreto de Urgencia No. 012-2010, publicado el 18 de febrero del 2010, donde se introdujo, por primera vez, el concepto de minería ilegal. Así, la minería ilegal pasó a ser aquella que se realiza en zonas de exclusión de minera, como la establecida en ciertas zonas del Departamento de Madre de Dios. Esta norma fue la primera en reconocer la necesidad de atender los diversos conflictos generados por el desarrollo desordenado de la minera aurífera y el incumplimiento de la normatividad ambiental, de salud, de trabajo, tributaria y de minería en el Departamento de Madre de Dios ${ }^{(10)}$.

Las normas posteriores estuvieron dirigidas a erradicar las actividades perniciosas relacionadas a la minería no formal. Fue así que, a través de la Ley No. 29815, en el año 2012 se delegó en el Poder Ejecutivo la facultad de legislar en materias de minería ilegal, tras lo cual se publicó un grupo de Decretos Legislativos ${ }^{(11)}$ con la finalidad de erradicar la minería ilegal del territorio nacional. De esta manera, se modificaron tipos penales, se instauró un proceso de formalización de la minería ilegal y se establecieron diversas obligaciones aplicables a quienes realicen actividades vinculadas al comercio y transporte de oro, entre otras.

Fue recién con este grupo de normas que se diferenció expresamente el término minería ilegal| ${ }^{(12)}$ de la minería informal(13). En términos generales, la minería ilegal es definida como aquella actividad que se desarrolla en zonas no aptas y prohibidas para su ejercicio; por ejemplo, las áreas naturales protegidas, sean reservas nacionales, parques nacionales o zonas de amortiguamiento; mientras que la minería informal es definida como aquella actividad minera que, si bien se desarrolla en zonas aptas para llevar a cabo dicha actividad, no ha cumplido con los trámites exigidos por la ley para su operación formal.

La importancia de comprender tal distinción radica en que sólo aquellos mineros considerados como informales podrían acogerse a la formalización de sus actividades; es decir, el Estado ha permitido que dicha actividad minera pueda corregirse a efectos de que se desarrolle en el marco de la legalidad (Caro 2016, 253). Como consecuencia directa de ello, las actividades comerciales realizadas por los mineros informales, siempre y cuando hayan iniciado el Proceso de Formalización, serán consideradas legales ${ }^{(14)}$. En cambio,

(10) La decisión del gobierno partió del reconocimiento de estudios que indican las graves consecuencias en la salud de las personas, por la precariedad e insalubridad que se experimenta en las áreas donde se explota el mineral, así como de la problemática social vinculada a la trata de personas, la transgresión a los derechos laborales, el trabajo infantil, la prostitución y la evasión tributaria.

(11) Nos referimos a los Decretos Legislativos No. 1099, 1100, 1101, 1102, 1103, 1104, 1105, 1106 y 1107, publicados entre los meses de febrero y abril del año 2012.

(12) Se definió en el Decreto Legislativo No. 1100, el cual fue posteriormente modificado por el artículo 2 del Decreto Legislativo No. 1105.

(13) Véase artículo 2 del Decreto Legislativo No. 1105.

(14) El Proceso de Formalización de la Minería Informal se creó mediante Decreto Legislativo No. 1105 con el propósito de 
la actividad realizada en el marco de la minería ilegal no podrá ser objeto de formalización y, además, será un delito, conforme a la modificación del Código Penal introducida por el Decreto Legislativo No. 1102, donde se tipificó el delito de minería ilegal, así como sus formas agravadas, el cual podrá ser cometido por mineros informales en caso no se hayan acogido al proceso de formalización; y que al tratarse de mineros ilegales siempre se configurará, pues no existe posibilidad de formalización.

\section{Principales herramientas jurídicas contra la minería ilegal}

Como se ha visto en el segundo apartado, la respuesta reguladora estatal frente a conductas contrarias al ordenamiento es de carácter mixto, pues entre ellas se encuentran medidas de carácter penal y administrativo. Dentro de esa lógica, creemos que la doctrina no se ha ocupado en forma integral de la evaluación de la regulación que el Estado ha planteado para frenar la minería ilegal y sus consecuencias -lo que es una característica de la delincuencia de la globalización- por lo que, a continuación, analizaremos las principales herramientas que forman parte de esa regulación. Se encontrará que ambos ejes, penal y administrativo, se complementan y que, en algunos casos, el segundo define la eficacia del primero.

\subsection{Herramientas penales}

A continuación se abordarán las principales figuras delictivas que sancionan diferentes aspectos del fenómeno de la minería ilegal. En primer término, se aborda el delito de minería ilegal, que sanciona la realización de actividad minera perjudicial, llevada a cabo sin la autorización administrativa correspondiente; luego, se analizan dos modalidades del delito de comercio clandestino, las cuales sancionan a quienes comercian o transportan bienes fiscalizados como el producto minero- por rutas fiscales distintas a las dictadas por el Ministerio de Transportes y Comunicaciones (En adelante, "MTC") o que, encontrándose en tales rutas, evadan los puestos de control fijados por la Superintendencia Nacional de Aduanas y de Administración Tributaria (En adelante, "SUNAT"). En tercer lugar, se examina la configuración de las tres modalidades que componen el tipo básico del delito de lavado de activos y se evalúa el más relevante pronunciamiento de la Corte Suprema de Justicia sobre el asunto. En los dos primeros delitos se repara, además, en las múltiples remisiones a normas reglamentarias y los criterios uso de las normas penales en blanco.

\subsubsection{El delito de minería ilegal}

El delito de minería ilegal fue introducido en el año 2012 por el Decreto Legislativo No. 1102 y se encuentra previsto en el artículo 307-A del Código Penal. Este llícito establece dos modalidades que se encuentran sancionadas con la misma pena. El primer supuesto sanciona a los agentes cuya conducta reúna los siguientes elementos típicos: (i) realicen actividad minera (en cualquiera de sus fases de exploración, extracción o explotación) de recursos de minerales tanto metálicos como no metálicos; (ii) no cuenten con autorización administrativa; y (iii) que dicha actividad cause o pueda causar perjuicio o alteración al ambiente.

Por su parte, el segundo supuesto sanciona con la misma pena a aquellos que se encuentren fuera del proceso de formalización de la pequeña minería y minería artesanal, y desplieguen la actividad descrita en el párrafo precedente. No obstante, en aras de verificar la consumación del delito en sus dos modalidades, es necesario realizar un análisis

establecer los requisitos, plazos y procedimientos que deberán seguir los mineros que realicen actividades sin cumplir con las exigencias de carácter administrativo, técnico, social y medioambiental, pero que pretendan formalizarse. Es decir, estableció el proceso para que los Mineros Informales puedan adquirir la condición de Mineros Formales. El Proceso de Formalización implica las siguientes etapas: (i) Presentación de la Declaración de Compromisos; (ii) Acreditación de titularidad, Contrato de Cesión, Acuerdo o Contrato de Explotación sobre la Concesión Minera; (iii) Acreditación de Propiedad o Autorización de Uso del Terreno Superficial; (iv) Autorización de Uso de Aguas; (v) Aprobación del Instrumento de Gestión Ambiental Correctivo; y, (vi) Autorización para Inicio/Reinicio de actividades de exploración, explotación y/o beneficio de minerales. 


\section{Vanessa Sofía Valverde Luna y Diego Alonso Collantes Añaños}

normativo concordado con lo que prescriben tanto el Decreto Legislativo No. 1351, como el Decreto Legislativo No. 1293, normas de carácter extrapenal.

El Decreto Legislativo No. 1351, publicado en de enero del 2017, estableció en su Única Disposición Complementaria Final, dos supuestos de exención de responsabilidad penal por la comisión del delito de minería ilegal. A través de esta Disposición, se estableció que el sujeto activo no es responsable penalmente, si (i) encontrándose en proceso de formalización, la autorización final de inicio o reinicio de operaciones mineras no pudo obtenerse por culpa del funcionario a cargo del proceso de formalización; o, (ii) si, encontrándose fuera del proceso de formalización, el sujeto activo se inserta en el Registro Integral de Formalización Minera, dentro del plazo establecido en el Decreto Legislativo No. 1293.

A su vez, el Decreto Legislativo No. 1293 dispuso la creación del proceso de formalización minera integral de la pequeña minería y minería artesana/(15), el cual se encuentra a cargo de la Dirección General de Formalización Minera del Ministerio de Energía y Minas. Así, en su artículo 4.1.3 se fijó la creación del Registro Integral de la Formalización Minera, el cual comprende, entre otros, a las personas naturales que desarrollan pequeña minería o minería artesanal de explotación ${ }^{(16)}$.

En ese orden de ideas, se ha de advertir que el contenido del numeral 4.2 del mismo artículo, al cual se remite la citada exención de responsabilidad penal del Decreto Legislativo No. 1351, indica que las inscripciones de las personas naturales que se encuentren desarrollando actividades de pequeña minería o de minería artesanal de explotación, se realizarán a partir del 06 de febrero del 2017 hasta por un plazo de 120 días hábiles en adelante, ante la SUNAT.

De lo anterior se deduce que, únicamente estarán exentas de responsabilidad penal aquellas personas que, a pesar de haber desplegado los elementos típicos del delito de minería ilegal, ya sea por medio de la pequeña minería o la minería artesanal, hayan realizado en conjunto las siguientes acciones: (i) Haber solicitado y logrado exitosamente su incorporación al Registro Integral de Formalización Minera(17), el cual se encuentra a cargo la de Dirección General de Formalización Minera del Ministerio de Energía y Minas; (ii) Que tal incorporación se haya efectuado entre el 06 de febrero del 2017 y los siguientes 120 días, los cuales caducaron el 06 de junio del 2017.

Como se puede notar, la actual configuración del delito de minería ilegal hace necesarias, múltiples remisiones a normas extrapenales

(15) Artículo 3. Proceso de formalización minera integral

3.1. Créase el proceso de formalización minera integral de la pequeña minería y minería artesanal, a cargo de las Direcciones y/o Gerencias Regionales de Energía y Minas, o de quienes hagan sus veces, en el marco de sus competencias.

3.2. Para su ejecución se realizarán las siguientes medidas:

1. Creación del Registro Integral de Formalización Minera, el cual está a cargo de la Dirección General de Formalización Minera del Ministerio de Energía y Minas.

Tiene por objeto identificar los sujetos comprendidos dentro del proceso de formalización minera integral.

2. Simplificación de los mecanismos administrativos para la formalización minera.

(16) Artículo 4. Registro Integral de Formalización Minera

4.1 Forman parte del Registro Integral de Formalización Minera:

(...)

3. Excepcionalmente, las personas naturales que se encuentren desarrollando actividades de pequeña minería o de minería artesanal de explotación, que cumplan con las condiciones establecidas en el artículo 91 del Texto Único Ordenado de la Ley General de Minería, aprobado por el Decreto Supremo No. 014-92-EM, y que además realicen su actividad en una sola concesión minera, a título personal y que cuenten con inscripción en el Registro Único de Contribuyentes.

(17) O que, a pesar de haber solicitado su incorporación al registro, no la hayan logrado por negligencia del funcionario público encargado, conforme establece el literal a. de la Única Disposición Complementaria Final del Decreto Legislativo No. 1351. 


\section{Alcances para una respuesta jurídica integral al comercio ilegal de oro Approaches for a comprehensive regulatory response to illegal gold commerce}

a fin de corroborar tanto el elemento típico de autorización administrativa, como -sobre todo- la aplicación o inaplicación de las exenciones previstas. Creemos que este hecho contribuye a que, desde una perspectiva práctica, su uso por parte de los operadores de la administración de justicia sea tanto defectuoso como insuficiente; prueba de ello es que, según declaraciones de la Ministra de Ambiente, en enero del 2017 tan sólo habían 89 sentencias por minería ilegal dentro de un universo de 1900 procesos penales, de las cuales tan sólo 4 fueron con pena efectiva ${ }^{(18)}$. Por otro lado, consideramos que este enfoque punitivo, si bien necesario, es incompleto ya que no sanciona el otro lado de la cadena comercial, esto es el adquirente de oro proveniente de la minería ilegal, sino únicamente a los mineros productores ${ }^{(19)}$.

Al respecto, una parte de la incipiente doctrina que existe sobre minería ilegal sostiene que una propuesta razonable sería que no sólo se proscriba a un sector de la cadena de comercialización del mineral ilegal, que es la producción; sino que se sancione a quienes realicen cualquier acto de promoción del tráfico del mineral ilegal, principalmente la compra y la venta del mineral ya extraído (Huamán Castellares 2016); postura con la que coincidimos, ya que es innegable que existe un conjunto de personas naturales y jurídicas, que realizan actos concretos de tráfico del mineral obtenido ilegalmente, o que participan en la comercialización del mineral y gozan de impunidad, al no haber tipificación alguna sobre tales actos.

Con la creación de un nuevo tipo penal que sancione actos de tráfico de minerales ilegales, la política criminal por la que ha optado el legislador sería más eficaz y coherente, pues influiría en una parte crucial de la cadena comercial: la circulación de mineral ilegal. Actualmente, este espacio de impunidad pretende ser cubierto a través del delito de lavado de activos; sin embargo, éste presenta mayores estándares de acreditación probatoria y una estructura más compleja, como se verá más adelante.

Por último, cabe advertir que nos encontramos frente a una ley penal en blanco de carácter impropio, ya que la configuración de este delito exige una remisión a otras leyes especiales del mismo rango (decretos legislativos). Al tratarse de remisiones a normas con semejante rango legal, su utilización no representa una infracción del principio de legalidad en sentido estricto, ni es una ruptura del mandato de determinación (lex certa), ya que de la interpretación de ambas normas es posible delimitar los criterios que determinan la conducta punible; aunque sí se trata de una dificultad práctica para su aplicación efectiva.

\subsubsection{El delito de comercio clandestino}

En marzo del 2012, año clave para la regulación sobre minería ilegal, se publicó el Decreto Legislativo No. 1103, el cual estableció medidas de control y fiscalización en la distribución, transporte y comercialización de insumos químicos que puedan ser utilizados en la minería ilegal; así, entre otras cosas, dicha norma amplió sustancialmente el tratamiento del delito de comercio clandestino, previsto en el artículo 272 del Código Penal; pues se agregaron los numerales 4 y 5 , con características de leyes penales en blanco propias, y de cuyos elementos nada se ha dicho, hasta la fecha, desde la doctrina.

Comenzaremos con el numeral 5, que sanciona a quien "utilice rutas distintas a las rutas fiscales en el transporte o traslado de bienes, insumos o productos sujetos a control y fiscalización", pues a partir del razonamiento allí empleado se desprenderá tanto una interpretación, como una crítica aplicable al numeral 4 , que reprime al que "evada el control fiscal en la comercialización, transporte o traslado de bienes sujetos a control y fiscalización dispuesto por normas especiales".

Se debe comenzar por advertir que la modalidad sancionada en el numeral 5 posee dos elementos típicos, a saber: (i) la utilización de rutas distintas a las rutas fiscales en el transporte o traslado de bienes, insumos o productos; $y$, (ii) que tales los bienes, insumos o productos transportados o trasladados tengan la calidad de bienes sujetos a control y fiscalización.

En ese orden de ideas, es indispensable notar que el término "bienes, insumos o productos 


\section{Vanessa Sofía Valverde Luna y Diego Alonso Collantes Añaños}

sujetos a control y fiscalización" debe ser entendido al amparo del Decreto Legislativo No. 1107, "que establece medidas de control y fiscalización en la distribución, transporte y comercialización de maquinarias y equipos que puedan ser utilizados en la minería ilegal, así como del producto minero obtenido en dicha actividad" (énfasis agregado)(20).

En esa perspectiva, los artículos 3 y 9 del aludido Decreto Legislativo indican que el producto minero será un bien sujeto al control y fiscalización de la SUNAT ${ }^{(21)}$, lo que a su vez debe ser concordado con la Tercera Disposición Complementaria Final, que señala que dicho control y fiscalización se aplicará al oro y a las aleaciones que incluyan oro, cualquiera sea su denominación. De ahí que, todo mineral aurífero posea la calidad de un bien sujeto a control y fiscalización, en los términos del numeral 5 del artículo 272 del Código Penal.

No obstante, como se ha visto, existe otro elemento típico, que consiste en "la utilización de rutas distintas a las rutas fiscales en el transporte o traslado de bienes, insumos o productos". El elemento utilización de rutas distintas a las rutas fiscales debe ser entendido en relación con lo dispuesto en el artículo 4 del citado Decreto Legislativo No. 1107, donde se señala que el transporte de los productos mineros, así como de equipos y maquinarias, deberá ser efectuado en las Rutas Fiscales establecidas por el Ministerio de Transportes y Comunicaciones a propuesta de la SUNAT, cuyo uso será obligatorio para el transporte del producto minero y maquinaria.

Por consiguiente, para que una conducta sea subsumida en el supuesto previsto por el numeral 5 del delito de comercio clandestino, será necesario que no se cumpla con transportar el bien, insumo o producto controlado, por las rutas fiscales establecidas, a través de normas especiales, por el MTC sobre el particular. Así las cosas, solamente será responsable del numeral 5 del delito de comercio clandestino, aquel que despliega simultáneamente los dos elementos típicos descritos; esto es que (i) utilice rutas distintas a las rutas fiscales en el transporte o traslado de bienes, insumos o productos; y, (ii) tales bienes, insumos o productos se encuentren sujetos a control y fiscalización, como el oro.

Ahora bien, a la fecha se han emitido múltiples rutas fiscales, así como puestos de control de la SUNAT en cada una de ellas, donde se ejerce la fiscalización sobre diversos bienes regulados, como, por ejemplo, los insumos utilizados en el tráfico de drogas y en la minería ilegal, entre otros. Sin embargo, actualmente, las únicas rutas fiscales que regulan el transporte del producto minero en el territorio de la república se circunscriben, exclusivamente, al transporte hacia el departamento de Madre de Dios. Efectivamente, se trata de la Resolución Ministerial 350-2013 MTC/02, que en su artículo 6 indica que las vías de transporte terrestre que deberán considerarse como rutas fiscales del producto minero, serán aquellas detalladas en la Resolución

(18) Véase SPDA Actualidad Ambiental, "Nuevos decretos sobre minería ilegal y minería informal," https://www.youtube.com/ watch?time_continue=2\&v=vx7S9il0Eac (consultada: de 1 de octubre de 2017) Conferencia de Prensa Multisectorial presentada con ocasión del nuevo proceso de formalización minera integral. Lima, enero 2017.

(19) Lo mismo puede decirse del relegado artículo 307-C del Código Penal, que sanciona el delito de financiamiento de la minería ilegal.

(20) Esto en cuanto a bienes y productos fiscalizados, pues los insumos deben ser leídos bajo lo dispuesto en el Decreto Legislativo No. 1103.

(21) Artículo $3^{\circ}$. - Del Control y Fiscalización de Maquinarias, Equipos y Productos Mineros

La SUNAT controlará y fiscalizará el ingreso, permanencia, transporte o traslado y salida de maquinarias y equipos utilizados en la actividad minera, y de los productos mineros, así como la distribución, hacia y desde el territorio aduanero y en el territorio nacional, sin perjuicio de las competencias de otras entidades del Estado, de conformidad con la legislación vigente. Artículo 9.- Comercialización de Productos Mineros

La SUNAT podrá aplicar controles especiales para la comercialización de los productos mineros dentro del ámbito de su competencia. Los productos mineros, cualquiera sea su estado, se sujetan a los alcances del presente Decreto Legislativo en lo referido a las Rutas Fiscales y sus controles. 


\section{Alcances para una respuesta jurídica integral al comercio ilegal de oro Approaches for a comprehensive regulatory response to illegal gold commerce}

Ministerial No. 360-2012-MTC/02, donde se fijan las rutas Lima-Cusco-Iñapari y Mollendo-Juliaca-Iñapari.

Si el propósito del Decreto Legislativo No. 1103, fue la ampliación de las hipótesis típicas del delito de comercio clandestino para penalizar el transporte del producto obtenido de laminería ilegal, creemos que no se ha cumplido con tal finalidad. Esto se explica por la ausencia de rutas fiscales al transporte de mineral que cubran el trayecto desde Madre de Dios y otros puntos de acopio hacia la ciudad de Lima, así como a puntos de frontera cercanos como Bolivia. Por ello, estimamos necesario que las normas extrapenales -rutas fiscales fijadas por Resolución Ministerial- que completan la consumación de este delito sean ampliadas; de lo contrario, su aplicación será defectuosa, ya que es evidente que el mineral no ingresa a las zonas de extracción, por ejemplo Madre de Dios, sino que sale de éstas zonas con fines de integración en la cadena comercial nacional e internacional.

Cabe decir que esta modalidad del delito de comercio clandestino corresponde a una ley penal en blanco propia, pues para completar su tipicidad es necesario remitirse a normas extrapenales de rango inferior, ya que son resoluciones ministeriales del MTC las que determinan el ámbito geográfico de las rutas fiscales por donde debe ser trasladado el producto minero, así como los insumos y la maquinaria empleada en la minería ilegal.

Pese a los errores descritos en el párrafo precedente, los cuales pueden subsanarse con la emisión de rutas fiscales adicionales, creemos que la estructura de este delito no vulnera el mandato de determinación impuesto por el principio de legalidad, pues la delimitación extrapenal del ámbito geográfico del elemento "ruta fiscal", es conforme con la teoría de la concreción, según la cual una ley penal en blanco propia es válida cuando establece criterios de decisión que determinan la conducta prohibida y las normas de menor rango únicamente especifiquen o concreten tales criterios (García Cavero 2007).

De otro lado, con relación al principio de lesividad en su manifestación de exclusión de meras contravenciones administrativas, existe identidad del bien jurídico protegido tanto por la ley penal como por las normas administrativas que la concretan, pues ambas fueron expedidas con la finalidad de frenar combatir la minería ilegal $y$, por tanto, proteger el medio ambiente ${ }^{(22)}$.

Finalmente, en el numeral 4 se sanciona el transporte o comercio de bienes sujetos a control y fiscalización siempre que se haya evadido el control fiscal. Creemos que se trata de un error de técnica legislativa, pues su redacción puede confundirse con la del numeral 5; no obstante, debe entenderse, desde una perspectiva restrictiva, que este supuesto sólo podrá cometerse por quien, encontrándose ya en una ruta fiscal, evada allí el o los puestos de control implementados por la SUNAT, en tanto que supuestos de evasión fiscal distintos ya están cubiertos por leyes penales especiales, como la Ley de Delitos Aduaneros, Ley No. 28008 y la Ley Penal Tributaria, Decreto Legislativo No. 813. Por el contrario, estimamos que sería un error entender que todo acto de comercio o transporte que, en general, evada el control fiscal, se encuentra dentro del ámbito punitivo de esta modalidad, pues tal interpretación no cumple con establecer los criterios de decisión determinantes de la conducta prohibida; es decir, el modo o los modos en los que se puede evadir el control fiscal y, por tanto, nos situaría ante una ley penal en blanco propia que lesionaría el principio de legalidad y el mandado de determinación, de modo que sería inconstitucional.

3.1.3. El delito de lavado de activos: el tipo básico

El lavado de activos es un mecanismo punitivo que busca duplicar los costos de la comisión delictiva y el blanqueo de sus

(22) Ha sido necesaria, desde luego, una actualización del concepto iusnaturalista de bienes jurídicos y derechos individuales vinculados al Estado liberal clásico, pues con la industrialización, entre otros supuestos, se reconocieron bienes jurídicos tales como el medio ambiente. 


\section{Vanessa Sofía Valverde Luna y Diego Alonso Collantes Añaños}

ganancias derivadas, partiendo de la premisa de que el crimen organizado necesita legitimar el provecho que obtiene de sus actividades. En abril del 2012, tras la experiencia de otras leyes antilavado, entró en vigencia el Decreto Legislativo No. 1106 , en cuya exposición de motivos se plasmó textualmente lo siguiente:

“(...) actualmente asistimos a un preocupante incremento de la criminalidad vinculada con las actividades de minería ilegal, las cuales además de dañar gravemente el ecosistema, la vida y la salud de las personas, representan también una considerable desestabilización del orden socioeconómico, pues estas actividades ilícitas se encuentran estrechamente ligadas con el blanqueo de capitales, que buscan dar una apariencia de legalidad a bienes de origen delictivo e introducirlos indebidamente al tráfico económico lícito".

Así las cosas, esta norma introdujo supuestos agravados cuando los activos objeto de lavado provengan de la minería ilegal, reconoció expresamente que la minería ilegal constituía delito fuente del delito de lavado de activos y estableció tres modalidades distintas de comisión para el tipo básico.

La primera modalidad está prevista en el artículo $1^{\circ} \mathrm{del}$ citado Decreto Legislativo y sanciona los actos de conversión y transferencia. Estas conductas aluden a las etapas inicial e intermedia del proceso de lavado de activos y deben ser entendidas no sólo en sentido literal sino funcional, ya que los supuestos de este delito, por su naturaleza, no son estrictamente jurídicos en sentido convencional, sino que implican el uso de conceptos obtenidos de la experiencia criminológica, de modo tal que su análisis no puede ser semejante al que se aplica en la explicación de un delito tradicional como el robo (Prado, 2013).

Con ello en cuenta, por actos de conversión debe entenderse todas aquellas formas posibles de colocación o movilización primaria de dinero líquido; mientras que los actos de transferencia consisten en alejar los capitales o bienes convertidos de su origen ilícito y de su primera transformación, usualmente a través de numerosas operaciones financieras o la compra de bienes de elevado costo que son registrados a nombre de terceras personas, entre otras estrategias. Es importante recordar que, si bien a efectos didácticos la doctrina ha establecido que el lavado de activos se comete en las fases secuenciales de colocación, intercalación o ensombrecimiento e integración, éste es un proceso continuo y dinámico que puede incluso ejecutarse en sólo una o dos de ellas (Arbulú Ramírez, 2014).

La segunda modalidad, prevista en el artículo 2 , sanciona mediante diversos verbos dos categorías de conductas: los actos de tenencia y los de ocultamiento. Los actos de tenencia implican hacerse de los activos de manera efectiva, pues se refieren únicamente al acto que lleva a su tenencia fáctica. Por otro lado, la adquisición de un activo con transferencia de propiedad será entendida como un acto de ocultamiento, siempre y cuando tenga por finalidad ocultar su identificación, incautación o decomiso (García Cavero, 2013). Ambas modalidades forman parte del proceso de integración del lavado de activos, pues nos encontramos frente a bienes cuya conversión y transferencia previa se pretende encubrir.

La última modalidad del tipo básico, establecida en el artículo 3, sanciona a quien realiza el transporte o traslado de dinero o títulos valores cuyo origen ilícito conoce o debía presumir, siempre que sea con la finalidad de evitar la identificación de su origen, su incautación o decomiso; así como a aquél que hace ingresar o salir del país dichos bienes con la misma finalidad. El ámbito de punibilidad de esta modalidad no abarca los actos de traslados propios de poseedor de bienes de origen ilícito, ni tampoco los actos de entrega o transferencia, pues lo que se reprime es el acto de desplazar dinero o títulos valores de forma que no puedan ser identificados; es decir fuera del ámbito espacial que los vincularía fácilmente con el delito previo. Se trata, entonces, de actos periféricos ajenos a las etapas de colocación o ensombrecimiento, los cuales dan lugar a un posterior proceso de legitimación de los activos o, al menos, dejan abierta esa posibilidad. (García Cavero, 2013). 


\section{Alcances para una respuesta jurídica integral al comercio ilegal de oro Approaches for a comprehensive regulatory response to illegal gold commerce}

En esta modalidad existe un preocupante vacío, pues mientras la anterior ley penal contra el lavado de activos, Ley No. 27765, agrupaba bajo la modalidad de ocultamiento y tenencia, la conducta de transporte de bienes de origen ilícito con la finalidad de evitar su identificación, incautación o decomiso; el actual Decreto Legislativo No. 1106, pese a haberse creado con énfasis en el combate contra el lavado de activos proveniente de la minería ilegal e incluso haber creado una modalidad independiente que sanciona los actos de transporte y traslado, ha restringido su hipótesis típica únicamente al desplazamiento de dinero y títulos valores. De esta manera, se ha dejado, inexplicablemente, fuera del ámbito de punibilidad a bienes como el producto minero. Lamentablemente, este vacío legislativo no puede subsanarse vía interpretación, ya que los supuestos típicos son claros y pretender ampliarlos atentaría directamente contra del principio de legalidad, por lo que creemos indispensable una reforma que, de manera consecuente con el propósito de esta norma, incluya dentro de la modalidad de traslado y transporte, a bienes como el producto minero.

\subsubsection{Actual tratamiento jurisprudencial: el Primer Pleno Jurisdiccional Casatorio sobre lavado de activos}

A continuación, nos ocuparemos de los criterios establecidos en el pronunciamiento más reciente y relevante sobre la materia, el Primer Pleno Jurisdiccional Casatorio de las Salas Penales Permanente y Transitorias de la Corte Suprema de Justicia de la República, el cual se realizó con el objetivo de concordar criterios discrepantes sobre la interpretación del delito de lavado de activos, específicamente su autonomía y el estándar de prueba para su persecución procesal y condena ${ }^{(23)}$.

Es pertinente señalar que el citado Pleno Jurisdiccional se realizó a raíz de los efectos de la Casación No. 92-2017/ Arequipa, en la que se señaló que, si se quiere iniciar una investigación por el delito de lavado de activos, paralelamente se tiene que establecer, con grado de certeza, la actividad criminal previa. Con este criterio, el delito de lavado de activos se convertiría, injustificadamente, en aún más difícil de demostrar, generando con ello importantes espacios de impunidad.
El Pleno Jurisdiccional resolvió, a través de la Sentencia Plenaria Casatoria No. $1-2017 / \mathrm{ClJ}-43$, establecer como doctrina legal importantes lineamientos que, entre otros, son los siguientes. (i) la reafirmación del reconocimiento del delito de lavado de activos como un delito autónomo, tanto en términos materiales, como para los efectos de su persecución procesal; (ii) la referencia al origen delictivo debe responder a actividades criminales que tengan la capacidad de generar ganancias ilícitas y requerir el auxilio de operaciones de lavado de activos; (iii) para la admisión de una imputación por lavado de activos solo se requiere, como mínimo: (iii. a) desbalance patrimonial, entendido como operaciones sospechosas que deriven en incremento patrimonial injustificado; (iii. b) que el desbalance se deba a las conductas de los artículos 1, 2 y 3 del Decreto Legislativo No. 1106 (conversión, transferencia, ocultamiento, transporte, etcétera); y (iii. c) que existan indicios de ello, es decir, la inferencia de que el agente conocía o podía presumir el origen ilícito de los bienes (ello, a través de documentación idónea, como los informes de la UIF, reportes contables, tributarios y financieros); (iv) la noción de actividades criminales en cuanto al delito fuente no puede entenderse como la existencia concreta y específica de un precedente delictivo de determinada naturaleza, cronología, intervención o roles de agentes delictivos individualizados y objeto; bastará, pues, la acreditación de la actividad criminal de modo genérico, y para ello deberá emplearse la prueba indiciaria; $y$, (v) el estándar o grado de convicción no es el mismo durante el desarrollo de la actividad procesal o del procedimiento penal, pues varía progresivamente en intensidad; de modo que se distinguen los siguientes niveles

(23) Este Pleno Casatorio se realizó a requerimiento del Fiscal de la Nación, quien solicitó que se aborde la contradicción que representó la Sentencia Casatoria Vinculante No. 92-2017/Arequipa, con otras sentencias emitidas por la Corte Suprema de Justicia. Sin embargo, otras instituciones, como el Ministerio de Justicia y la Unidad de Inteligencia Financiera, cuestionaron la Sentencia Casatoria en referencia, pues consideraron que ponía en riesgo los procesos por lavado de activos en el país. 


\section{Vanessa Sofía Valverde Luna y Diego Alonso Collantes Añaños}

de acreditación, según la etapa del proceso penal, a saber: (v. a) diligencias preliminares: sospecha inicial simple; (v. b) formalización de la investigación: sospecha reveladora; ( $v$. c) acusación y emisión de auto de enjuiciamiento: sospecha suficiente.

Si bien los criterios desarrollados en el apartado precedente son un importante esfuerzo de la Corte Suprema para ordenar interpretaciones dispares, y contrarias a la seguridad jurídica en el delito de lavado de activos, lo cierto es que muchas de las dificultades propias de la naturaleza de este delito persisten. Una de las expectativas que se tenía era la relacionado a los estándares de acreditación del origen ilícito de los bienes, durante las distintas etapas de investigación y juzgamiento, pero lo concerniente a este punto en el Pleno Jurisdiccional Casatorio no constituye una herramienta especialmente novedosa para la investigación y juzgamiento del delito(24).

Otro de los puntos que ha quedado pendiente aún tras el Pleno Jurisdiccional Casatorio es el grado de conocimiento del origen delictivo de los bienes, en cuanto a los términos que debe precisarse. Este es un punto donde la jurisprudencia no ha profundizado, por lo que habría sido de utilidad establecer lineamientos generales que resulten aplicables al delito de minería ilegal como delito fuente; en atención a situaciones en las que, por ejemplo, el adquirente del mineral, quien tiene la obligación de acreditar la procedencia del mineral a partir de la verificación de una serie de documentos mínimos, sea sujeto de engaño por parte del vendedor del mineral, asunto del que nos ocuparemos en uno de los apartados siguientes.

Pensamos, entonces, en los siguientes escenarios: el adquirente del mineral que cumple con los requisitos de la norma administrativa y aun así se hace con mineral obtenido ilegalmente ¿sería posible atribuirle el conocimiento, bajo el supuesto que debía presumir que el mineral adquirido tenía procedencia ilícita? Con excepción de algunos casos particulares, donde es evidente que la información de los documentos no corresponde con la realidad, ¿cómo se puede establecer el grado de conocimiento requerido por el tipo penal de lavado de activos, si es que el adquirente cumplió con las obligaciones administrativas tal como se encuentran reguladas en la actualidad?

Por otro lado, subsisten complicaciones inherentes a la configuración del delito de lavado de activos, y por tanto no atribuibles al desarrollo jurisprudencial, como las dificultades de motivación que conlleva la prueba indiciaria, a la cual habrá que recurrir en la mayoría de casos para comprobar la actividad criminal precedente. Consideramos por tanto que, en razón de sus particulares exigencias, el lavado de activos debe entenderse como una herramienta penal complementaria a los tipos penales que atacan directamente la actividad ilícita, como la minería ilegal y algunas modalidades del comercio clandestino; sin embargo, dado que estos últimos no han demostrado eficacia, por motivos ya explicados en los apartados precedentes, su utilización complementaria corre el riesgo de convertirse en principal, desnaturalizando así la política criminal del Estado.

\subsection{Herramientas administrativas}

En este apartado se examinarán distintos elementos de naturaleza administrativa que forman parte de la regulación que el Estado ha planteado contra la minería ilegal y el comercio ilegal de oro, o que influyen sobre éstos. Se comienza con la explicación del funcionamiento de las rutas fiscales introducidas por una ley y desarrolladas por el MTC, que, como se ha visto, están además vinculadas a dos modalidades del delito de comercio clandestino. En segundo lugar, se

(24) En efecto, la Corte Suprema ya se había expresado en el Recurso de Nulidad No. 2868-2014/Lima (de fecha 27 de diciembre de 2016), sobre los niveles de acreditación de la procedencia delictiva de los activos lavados; donde señaló que "lo que realmente exigido es la acreditación necesaria, como elevada probabilidad objetiva, de que los bienes, inicialmente bajo sospecha simple, que es lo que se precisa para la legitimidad de la investigación preparatoria en fase preliminar, y, luego, bajo sospecha suficiente, en que, el nivel de prognosis, se requiere que la condena resulte probable (probabilidad de condena), y que a su vez justificada la acusación y el auto de enjuiciamiento, tuvieron su origen en una actividad delictiva previa". 


\section{Alcances para una respuesta jurídica integral al comercio ilegal de oro Approaches for a comprehensive regulatory response to illegal gold commerce}

evaluará la responsabilidad del transportista de mercancías en relación a las obligaciones que le son aplicables según el Decreto Supremo No. 17-2009-MTC. En el siguiente punto, se analiza la responsabilidad del comprador de productos mineros, según lo establecidos en las normas especiales y, por último, se realizan comentarios sobre el estado del proceso de formalización impulsado de los mineros informales.

\subsubsection{Las rutas fiscales}

Las rutas fiscales fueron introducidas por el Decreto Legislativo No. 1103 con el propósito de controlar y fiscalizar la distribución, transporte y comercialización de los insumos químicos que puedan ser utilizados en la minería ilegal. Posteriormente, con el Decreto Legislativo No. 1107 se amplió su ámbito de aplicación al transporte y comercialización del producto minero, así como la maquinaria y equipos que pueden ser utilizados en la minería ilegal(25), conforme se ha visto en el apartado donde se abordó el delito de comercio clandestino.

Bajo ese esquema, las rutas fiscales son elementos de control geográficos fijados a través de Resoluciones Ministeriales del MTC, donde se fiscalizan 3 tipos de bienes: el producto minero (mineral aurífero), insumos utilizados en la minería ilegal y maquinaria utilizada en la minería ilegal. Creemos que este mecanismo es potencialmente idóneo para dificultar, en términos de incremento de costos, la cadena de comercialización de la minería ilegal, siempre y cuando los puestos de control de la SUNAT, que deben existir en cada ruta fiscal, funcionen adecuadamente.

Sin embargo, actualmente subsiste un inexplicable vacío ya advertido en el apartado dedicado al delito de comercio clandestino; se trata de la existencia de sólo una ruta fiscal aplicable al comercio o transporte del producto minero, la cual, además, únicamente comprende tramos en dirección al departamento de Madre de Dios. Una regulación de este tipo sobre el producto minero no sólo es insuficiente, sino también incongruente; ya que el producto minero no llega a Madre de Dios, sino que sale desde él hacia la ciudad de Lima, especialmente al aeropuerto, o hacia la cercana frontera con Bolivia, para aprovechar el menor rigor de la fiscalización. En este escenario, lo coherente sería que se creen rutas fiscales aplicables al producto minero que parte desde Madre de Dios, o zonas aledañas donde se sabe que el mineral precioso es acopiado, hacia dichas locaciones, con el objetivo de detectar, inmovilizar e incautar todo cargamento que no presente los documentos de sustento necesarios sobre el origen lícito del oro, lo que deberá ser posteriormente corroborado a través de la respectiva investigación fiscal y/o procedimiento administrativo.

\subsubsection{El Reglamento Nacional de} Administración de Transporte y las empresas transportistas de valores

Las empresas transportistas de mercancías, dentro de las que se incluyen las empresas de transporte de valores (oro, dinero, entre otros), se encuentran reguladas con carácter general por el Reglamento Nacional de Administración de Transporte - Decreto Supremo No. 17-2009-MTC (en adelante, "el Reglamento"). Particularmente, las empresas transportistas de valores, que son pocas, pero muy conocidas en el mercado por sus vehículos blindados, se hallan dentro de la categoría de Servicio de Transporte Público, que según el artículo 3.60 del Reglamento consiste en el servicio de transporte terrestre de personas, mercancías o mixto que es prestado por un transportista autorizado para dicho fin, a cambio de una contraprestación económica.

Adicionalmente, el artículo 45 del citado Reglamento contiene un listado específico de las condiciones de operación con las que se debe cumplir para realizar el transporte de mercancías por vía terrestre, siendo que la más relevante para el tema que nos ocupa es aquella contenida en el numeral 45.1.2., donde se señala que dentro de las condiciones

(25) Cabe señalar la aplicación de rutas fiscales luego fue extendida al control y fiscalización de insumos que puedan ser utilizados en la elaboración de drogas ilícitas, mediante el Decreto Legislativo No.1126. 


\section{Vanessa Sofía Valverde Luna y Diego Alonso Collantes Añaños}

específicas de operación que se deben cumplir para prestar el servicio de transporte público de mercancías está "recepcionar la mercancía entregada por el usuario, en las condiciones pactadas".

De lo anterior se entiende que la ley no prevé un marco referencial detallado para el modo en que una empresa de transporte de valores -por ejemplo, mineral aurífero- debe recibir y transportar la mercancía(26), por lo que este será definido en las cláusulas del contrato de transporte suscrito con el remitente. Esto es confirmado por el artículo 84.2. del Reglamento, donde se señala expresamente que los transportistas establecerán las cláusulas generales de contratación que regirán los contratos de transporte que celebren.

Al amparo de esta normativa, es conocido que en la realidad las compañías de transporte de valores brindan sus servicios bajo una modalidad donde los bienes que son materia de recojo, traslado y entrega se encuentran en bolsas cerradas y precintadas, por lo que no se comprueba su contenido más allá de lo declarado por el remitente, que queda reflejado en las guías de remisión. Simultáneamente, es también sabido que una vez que el oro proveniente de la minería ilegal es acopiado por empresas nacionales comercializadoras con apariencia de legalidad, éstas proceden a venderlo como lícito a empresas multinacionales importadoras que pueden o no conocer de su origen real. Así, es especialmente en esta etapa de la cadena comercial que se hace prácticamente indispensable, para los agentes comercializadores intervinientes, la contratación de empresas de transporte de valores, en atención al elevado importe de la mercancía objeto de la operación de compraventa.

Sin embargo, el margen discrecional otorgado por el Reglamento, en adición a la modalidad del traslado empleado por las empresas de transporte de valores, es un espacio que puede ser utilizado por las redes criminales de minería ilegal, con el propósito que no se conozca el origen ilícito del producto minero. El hecho que el Reglamento no exija a los transportistas requerir información mínima de la procedencia del mineral que transportan, es contrario a una política de Estado que tiene por objetivo erradicar la minería ilegal y la comercialización del producto minero obtenido de ella.

Sobre la base de esta falencia, consideramos esencial implementar una modificación del artículo 45 del Reglamento Nacional de Administración de Transporte, a fin de agregar dentro de las condiciones del servicio de transporte, la exigencia de requerir al remitente documentación mínima que acredite el origen lícito de la mercancía cuando se trate de mineral aurífero; lo que, además, sería consecuente con la condición de bien controlado y fiscalizado que el oro posee.

3.2.3. Responsabilidad del adquirente de productos mineros

El adquirente de mineral es uno de los actores más importantes dentro de la cadena de comercialización del oro. La legislación sobre minería ilegal ha establecido obligaciones para estos sujetos, pese a que no son quienes realizan directamente las actividades mineras extractivas; se trata básicamente de dos obligaciones a cargo de quienes adquieren mineral aurífero: (i) verificar el origen del mineral a ser adquirido ${ }^{(27)}$ y (ii) mantener un registro de compra de oro ${ }^{(28)}$.

Empecemos por el último de los requisitos. El artículo 5 del Decreto Supremo No. 0122012-EM establece que los comercializadores de oro deberán crear y mantener un registro actualizado, en medio electrónico, donde quede registrada la siguiente información respecto de cada compraventa de oro: (i) el nombre o denominación del vendedor, según sea persona natural o jurídica; (ii) el número de

(26) El artículo 45 del Reglamento hace referencia a condiciones específicas de operación para prestar el transporte público de mercancías, pero todas ellas se remiten a aspectos de seguridad, carga y descarga de la mercancía.

(27) Primer párrafo del artículo 11 del Decreto Legislativo No. 1107.

(28) Artículo 5 del Decreto Supremo No. 012-2012-EM. 


\section{Alcances para una respuesta jurídica integral al comercio ilegal de oro Approaches for a comprehensive regulatory response to illegal gold commerce}

documento nacional de identidad o número de Registro Único de Contribuyente (En adelante, "RUC") del vendedor; y, (iii) el código de presentación de la Declaración de Compromisos de Formalización.

Este requisito no presenta mayor dificultad para los adquirentes de oro, contrariamente a lo que ocurre con el requisito de verificar la procedencia del mineral, obligación descrita en el artículo 11 del Decreto Legislativo No. $1107^{(29)}$, que en buena cuenta consiste en solicitar documentos sobre el origen del mineral y verificar la autenticidad de los datos consignados en los sistemas de información pertinentes, tales como el RUC, razón social, domicilio, código único de concesión minera, autorizaciones, datos del bien comercializado, datos de la guía de remisión y transportistas, entre otros. Es decir, tal obligación no consistiría en verificar, por sí mismo, el origen del mineral, sino solicitar los documentos que acrediten su procedencia.

Las fuentes de información públicas, donde el adquirente podría verificar los datos que le alcanza el vendedor del mineral son básicamente cuatro, a saber: (i) el Registro Nacional de Declaraciones de Compromisos (hoy denominado Registro de Saneamiento), que se puede obtener de manera actualizada en internet; (ii) el Registro de Comercializadores de Oro, donde se puede confirmar si una persona natural o jurídica que comercializa oro (ii.a) se encuentra inscrita y, en consecuencia, cumple con dicha obligación y (ii.b) si se trata de mineros formales o mineros informales en proceso de formalización ; (iii) la página web de la SUNAT, donde se puede verificar, entre otros, el número de RUC de cada compañía, su domicilio fiscal y sus actividades económicas; y (iv) los Registros de la Superintendencia Nacional de Registros Públicos (En adelante, "SUNARP"), donde se puede verificar la información relacionada al vendedor del mineral, tal como su denominación social, el nombre completo y documento de identificación del representante legal del vendedor y los poderes con los que cuenta para representarlo.

Sin embargo, la verificación en las fuentes de información pública para corroborar la información requerida en la obligación del adquirente, plasmada en el artículo $11 \mathrm{del}$ Decreto Legislativo No. 1107, ha demostrado ser insuficiente para lograr una aproximación veraz al origen del mineral. En la práctica, es usual que el adquirente de mineral solicite al vendedor una declaración jurada mediante la cual éste detalle la procedencia del mineral que está comercializando ${ }^{(30)}$, lo cual tampoco constituye una herramienta suficientemente útil para lograr el objetivo de la obligación: verificar el origen efectivo del mineral.

Así pues, la criminalidad relacionada a la minería ilegal se vale de datos de personas naturales y jurídicas que se encuentran comprendidas en el Registro de Comercializadores de minerales para consignarlos en las guías de remisión remitente o transportista; $y$, de esta manera, encubrir el verdadero punto de inicio del transporte/comercio del mineral, esto es, el origen del mismo. Adicionalmente, la experiencia casuística ha demostrado que estos mismos datos son indebidamente utilizados para suscribir declaraciones juradas con información falsa, que el vendedor de oro entrega al adquirente, con o sin su conocimiento.

(29) Artículo 11 del Decreto Legislativo No. 1107:

"Todo adquirente de productos mineros sujetos a control y fiscalización en el marco del presente Decreto Legislativo, cualquiera sea su estado, sin importar que la adquisición se realice en forma temporal o permanente, deberá verificar el origen de los mismos, solicitando los documentos que correspondan, debiendo verificar la autenticidad de los datos consignados en los sistemas de información que correspondan. Los datos mínimos a verificar serán los siguientes: a) RUC, razón social, nombre y apellido, así como documento de identidad, domicilio real del vendedor del mineral, Código Único de Concesión y su vigencia de donde proviene el mineral, y Autorización de Explotación; b) Los datos consignados en los comprobantes de pago, especificando su descripción, y los datos del bien comercializado (peso, características y estado); c) Datos de la guía de remisión y transportista (...)."

(30) En este mismo sentido, véase: Jáuregui, Gabriela y otros, "Nuevo esquema normativo penal aplicable a la minería ilegal," Derecho y Sociedad 39 (2012): 143-58. 


\section{Vanessa Sofía Valverde Luna y Diego Alonso Collantes Añaños}

En este punto en particular, creemos que la solución no estriba en solicitar más documentos de los señalados en el artículo 11 del Decreto Legislativo No. 1107, sino en crear una entidad pública, o se incentive a una privada, que tenga como una de sus funciones certificar el origen del oro, de modo que la identificación de su origen goce de razonable veracidad. Otra propuesta a considerar es la creación de un Banco de Fomento Minero ${ }^{(31)}$, que permita la adquisición, bajo ciertas condiciones, de la producción minera a un porcentaje del precio del mercado internacional, que sea superior al precio promedio que ofrecen los acopiadores de oro.

\subsubsection{Breves apuntes sobre el proceso de formalización}

La formalización, en general, es un proceso que tiene por objetivo el desarrollo de una actividad económica dentro el marco legal que la regula y, en cuanto a minería informal, lo que se busca es el desarrollo de esta actividad en condiciones de cumplimiento con condiciones mínimas de carácter ambiental, tributario y de seguridad, de modo que las principales externalidades negativas que genera sean mitigadas.

Como ya lo hemos adelantado, con la promulgación de la Ley No. 29815, de delegación de facultades al Poder Ejecutivo en el año 2012, se emitieron una serie de Decretos Legislativos destinados a erradicar la minería ilegal. Uno de ellos fue el Decreto Legislativo No. 1105, por el cual los mineros informales que se acogieron al proceso de formalización podrían proseguir con el mismo ${ }^{(32)}$ y culminarlo con las ventajas que la legalidad otorga, siempre que acrediten determinados documentos ${ }^{(33)}$. Uno de los documentos fue la Declaración de Compromisos vigente, a través del cual el minero se compromete, entre otros, a respetar las normas de minería y medio ambiente mientras realiza sus actividades. Tal declaración permite al minero desarrollar actividad minera mientras su formalización aún se encuentra en trámite.

Inicialmente, el Decreto Legislativo No. 1105 , en concordancia con las disposiciones establecidas en el Decreto Supremo No. 0322013-EM, dispuso como plazo máximo del Proceso de Formalización el 19 de abril del 2014. No obstante, a partir del 20 de abril del 2014 entró en vigencia el Decreto Supremo No. 029-2014-PCM, sobre Estrategia de Saneamiento de la Pequeña Minería y Minería Artesanal, a partir del cual se requirió a aquellos mineros en vías de formalización que cuenten con Declaración de Compromisos vigente, que acrediten también su inscripción en el RUC, ya que ello les permitirá formar parte del Registro de Saneamiento, y de esta manera generar que aquellos mineros en vías de formalización que iniciaron el proceso dispuesto en el Decreto Legislativo No. 1105, lo culminen.

Sin embargo, el proceso de formalización ha sido reabierto con la promulgación del Decreto Legislativo No. 1293, del 30 de diciembre del 2016. En él se dispuso la creación del proceso de formalización minera integral de la pequeña minería y minería artesana/(34), a cargo de la

(31) La creación de un Banco Minero, de las características expuestas, no es una novedad para nuestro país. En el año 1940 se creó el Banco Minero del Perú, el cual tenía como objetivo otorgar préstamos y, además, fomentar el desarrollo de la minería a través de la compra del oro, entre otros; dicha entidad fue disuelta en la década de 1990, como parte de las políticas de privatización del gobierno de aquel entonces.

(32) El Estado ha tenido anteriores intentos para regular la actividad minera. Así, se creó un régimen especial para la pequeña minería y minería artesanal, ello a través de la Ley No. 27651, Ley de Formalización y Promoción de la Pequeña Minería y la Minería Artesanal, promulgada el 24 de enero de 2002. Luego, se promulgó su reglamento a través del Decreto Supremo No. 013-2002-EM, el 21 de abril de 2002.

(33) Además de la Declaración de Compromisos, también era requisito la acreditación de titularidad, contrato de cesión o explotación, la autorización de uso de terreno superficial y la presentación del IGAC (Instrumento de Gestión Ambiental Correctivo).

(34) Artículo 3. Proceso de formalización minera integral 3.1 Créase el proceso de formalización minera integral de la pequeña minería y minería artesanal, a cargo de las Direcciones y/o Gerencias Regionales de Energía y Minas, o de quienes hagan sus veces, en el marco de sus competencias. 3.2 Para su ejecución se realizarán las siguientes medidas: 
Dirección General de Formalización Minera del Ministerio de Energía y Minas. Asimismo, a partir de lo indicado, se estableció, también, la creación del Registro Integral de la Formalización Minera, el cual comprende, entre otros, a las personas naturales que desarrollan pequeña minería o minería artesanal de explotación.

Esta norma puede ser entendida como una suerte de amnistía para los mineros que no se acogieron en el anterior proceso de formalización, iniciado en el 2012 (Decreto Legislativo No. 1105), pues prescribió que entre el 6 de febrero de 2017 y por 120 días adicionales, el registro estaría excepcionalmente abierto para quienes realicen su actividad en una sola concesión y que cuentan con su inscripción en el RUC.

La norma con rango de ley más reciente sobre la materia es el Decreto Legislativo No. 1336, publicado el 6 de enero del 2017, que establece la simplificación del procedimiento de formalización de minería integral, para lo cual se estableció el nuevo instrumento de Gestión Ambiental y Fiscalización para la Formalización de Actividades de Pequeña y Minería Artesanal. Se han planteado válidos cuestionamientos a esta norma debido a que flexibiliza la utilización maquinaria antes prohibida para la pequeña minería y minería artesanal, lo cual promovería el ingreso de mineros con una capacidad de producción mayor a la de un minero artesanal convencional, con lo que se beneficiarían de las menores exigencias ambientales y tributarias que también se contempla para este subsector (Calle y Valencia 2017). Peor aún, creemos que la exención de responsabilidad penal por minería ilegal contemplada en la disposición complementaria final del Decreto Legislativo No. 1351 es un grave desacierto ya que ha puesto en riesgo los, desde ya exiguos, procesos penales e investigaciones que se encontraban en curso, y simultáneamente mella aún más otro de los incentivos duros para la formalización: la aplicación del ius puniendi.

Con cifras que dan cuenta de cinco mil mineros formalizados de un total de setenta mil que iniciaron el proceso hasta finales del 2016, parece seguro decir que la formalización venía siendo un claro fracaso (García 2017). Si bien, los últimos dos Decretos Legislativos que entraron en vigencia proyectan la impresión de que nos encontramos ante un proceso más flexible, en comparación con las disposiciones del 2012; lo cierto es que todavía estamos ante altos niveles burocráticos que, aunados a la insuficiencia de operaciones de interdicción que generen un fuerte incentivo de ingresar a la legalidad, impiden variaciones sustanciales de la situación. La identificación de las causas específicas del continuo fracaso del proceso de formalización no pueden ser abordadas exclusivamente desde los saberes normativos, pues requiere ser examinada por estudios de campo que tengan el objetivo de conocer con detalle las perspectivas locales de los mineros informales, para luego evaluar si acaso se ha cometido un error en las premisas que fundamentan este instrumento 0 , de ser estas correctas, establecer qué mecanismos necesitan ser ajustados (Salo 2016).

\section{Sistema complejo: dinámica y actores al margen de la legalidad en la ruta de comercialización del mineral aurífero}

Como hemos planteado, combatir la minería ilegal y la comercialización ilegal de oro presupone tanto por parte de los legisladores como de los demás operadores que proveen enforcement la comprensión de la dinámica en la que estos fenómenos se insertan. El comercio del mineral aurífero proveniente de la minería ilegal en el Perú, puntualmente en la zona de Madre de Dios, ha sido objeto de un estudio a partir del cual se han identificado dos etapas principales en la cadena comercial: el acopio del oro y el blanqueo del oro,

1. Creación del Registro Integral de Formalización Minera, el cual está a cargo de la Dirección General de Formalización Minera del Ministerio de Energía y Minas.

Tiene por objeto identificar los sujetos comprendidos dentro del proceso de formalización minera integral.

2. Simplificación de los mecanismos administrativos para la formalización minera. 


\section{Vanessa Sofía Valverde Luna y Diego Alonso Collantes Añaños}

ambas necesarias para el ingreso del mineral al circuito legal (Sociedad Peruana de Derecho Ambiental 2015).

En la primera etapa, las personas naturales o jurídicas que realizan el acopio están caracterizadas por bodegas, bares, hostales y, en general, cualquier tipo de comercio que se encuentre en el yacimiento o campamentos aledaños, pues los productos o servicios que estos ofrecen son pagados con el oro extraído. En esta lógica, el esquema principal sería aquel en el cual los comercios locales transfieren el oro a los intermediarios locales; en la segunda etapa, éstos lo venden a empresas nacionales formalmente constituidas, que se dedican a la compra aparentemente legal de oro; finalmente, tales empresas venden el mineral a refinerías o empresas multinacionales que muchas veces también conocen de la procedencia ilícita; en este punto el mineral aurífero ya se encuentra completamente blanqueado al haberse alejado más de su origen.

Efectivamente, desde que el mineral pasa de los intermediarios a las empresas nacionales con apariencia de legalidad, éstas se preocupan en blanquearlo, a través de la utilización de datos de concesiones mineras que se encuentran en zonas permitidas para la actividad de extracción minera, pero que en realidad ya han agotado su capacidad de producción. El último eslabón de la cadena de comercialización son las refinerías extranjeras; los estudios realizados indican que, entre los años 2001 a 2004, el destino de exportación más importante de oro fue el Reino Unido, entre 2005 y 2007 Estados Unidos y, a partir del 2008, el destino más importante del oro peruano es Suiza (Sociedad Peruana de Derecho Ambiental 2015).

A manera ilustrativa, cabe señalar que esta dinámica comercial habría sido la empleada en el conocido caso de la red criminal liderada por Pedro Pérez Miranda (conocido bajo el seudónimo de Peter Ferrrari). Así, en enero del 2017, se intervino once viviendas y se detuvo a Pérez Miranda y a otras cinco personas, bajo la premisa que pertenecían a una red criminal dedicada al tráfico de minerales ilegales, así como al tráfico de drogas y corrupción de funcionarios. Según las investigaciones que dio a conocer el Ministerio Público, la red habría exportado entre el 2012 y 2014 más de trece toneladas de oro a través de empresas fachada (Redacción RPP 2017).

Estas empresas fachada eran creadas por personas allegadas a Pérez Miranda, ya sea familiares o subordinados laborales; y modalidad que emplearon para el blanqueo oro ilegal, fue -precisamente- la utilización de datos de personas naturales o jurídicas con concesiones mineras que, además, se encontraban registradas como comercializadores de oro ante el Ministerio de Energía y Minas. Estas empresas generaban también guías de remisión donde se indicaba falsos puntos punto de origen del traslado del mineral, para así encubrir su proveniencia ilícita. Una vez reunidos los documentos fraudulentos, los representantes de las empresas irregulares se presentaban a las sucursales $u$ oficinas que empresas internacionales mantenían en el Perú. Ahí se realizaba el inicio de la venta, para luego proceder a la exportación del mineral. Generalmente, cuando el mineral ingresaba al país de destino, se completaba el pago por el precio del mineral, finalizando así su comercialización en el ámbito nacional ${ }^{(35)}$.

Los datos conocidos de la aludida investigación apuntan a constatar que los requisitos exigidos

(35) Nuevamente a modo ilustrativo, conviene recordar que en diciembre del 2013 la SUNAT dispuso la excepcional inmovilización de 300 kilogramos de oro. El mineral pretendía ser exportado por una de las empresas fachada de Peter Ferrari hacia los Estados Unidos, cuando funcionarios de la SUNAT advirtieron que los documentos presentados para la exportación no acreditaban el origen lícito del mineral. Ante esta medida, la empresa fachada de Pérez Miranda logró la emisión de una medida cautelar en Ucayali para liberar el oro, lo cual efectivamente consiguió. En la consecución de esta medida cautelar habrían participado agentes de la red de Rodolfo Orellana Rengifo. Véase Castilla, Óscar. Investigan "secuestro" de 316 kilos de oro ilegal incautado. En Diario El Comercio. https://elcomercio.pe/peru/madre-de-dios/investigan-secuestro-316kilos-oro-ilegal-incautado-282040 (Consulta: 13 de noviembre de 2017). 


\section{Alcances para una respuesta jurídica integral al comercio ilegal de oro Approaches for a comprehensive regulatory response to illegal gold commerce}

a los agentes que intervienen en la comercialización de mineral aurífero son insuficientes para asegurar la circulación lícita del producto minero. Mientras no exista una entidad que certifique mínimamente, entre otras cosas, la procedencia del mineral, es probable los agentes comercializadores continúen utilizando documentos con información falsa.

\section{Conclusiones}

El presente trabajo ha pretendido otorgar una evaluación general y crítica sobre el funcionamiento y las limitaciones de las principales herramientas jurídicas que el Estado peruano ha planteado como parte de su respuesta normativa frente a la minería ilegal; dentro de esa pretensión, se encuentra también la expectativa de que los encargados de la política legislativa en este ámbito, tanto a nivel legal como reglamentario -así como sus aplicadores- sean conscientes de la necesidad de entender la dinámica comercial en la que este tipo de criminalidad organizada se inscribe.

En el ámbito de las herramientas penales analizadas nos hemos ocupado de los delitos de minería ilegal, comercio clandestino y lavado de activos. En el delito de minería ilegal, hemos advertido que las múltiples remisiones a normas extrapenales, incrementadas tras los últimos Decretos Legislativos No. 1351 y 1293, elevan la posibilidad de una aplicación defectuosa y/o insuficiente por parte de los operadores; de allí que exista, por lo menos, correlación con la cantidad ínfima de sentencias condenatorias (89) por este delito. Asimismo, estimamos que el enfoque punitivo adoptado con el delito de minería ilegal debe ser complementado con la creación de un tipo penal que sancione a quienes efectúen operaciones de compraventa sobre mineral de origen ilícito con conocimiento de su procedencia, de modo no sólo se sancione la parte productiva de la cadena comercial, sino también los elementos de su distribución.

En el delito de comercio clandestino, la modalidad prevista en el numeral 5 presenta una importante laguna de impunidad cuando se trata del transporte o traslado del producto minero, puesto que las únicas rutas fiscales aplicables a este supuesto se dirigen hacia el departamento de Madre de Dios desde Lima y Mollendo. Sin embargo, no existen rutas que cubran el transporte o traslado desde dicha localidad u otros puntos de acopio hacia Lima o zonas cercanas de frontera como Bolivia, en concordancia con la dinámica comercial del oro; por tanto, es necesario que el MTC emita nuevas rutas fiscales que comprendan estos trayectos. Por otro lado, la modalidad prevista en el numeral 4 debe ser interpretada restrictivamente, ya que de lo contrario vulnera el principio de legalidad y sería inconstitucional.

La aplicación del lavado de activos, debido a sus particulares exigencias de acreditación, debe ser vista como una herramienta complementaria a los ilícitos que aborden directamente la actividad criminal, como idealmente tendrían que ser los delitos vigentes de minería ilegal y comercio clandestino. La modalidad que sanciona los actos de transporte y traslado necesita ser reformada, para incluir dentro de sus elementos al producto minero, pues actualmente únicamente comprende el transporte de dinero o títulos valores.

Desde el ámbito administrativo nos hemos ocupado de las siguientes herramientas: las rutas fiscales, el reglamento nacional de administración de transporte, la responsabilidad del adquirente de productos mineros, así como algunos aspectos del proceso de formalización de la pequeña minería y minería artesanal. Las rutas fiscales son instrumentos potencialmente útiles para ejercer control sobre las principales vías de transporte de insumos y bienes utilizados en la minería ilegal. Sin embargo, mientras no se implementen rutas adicionales que cubran trayectos que van desde las zonas de extracción o acopio, no cumplirán su finalidad $y$, además, restarán eficacia a la modalidad del numeral 5 del delito de comercio clandestino.

El Reglamento Nacional de Administración de Transporte, otorga un amplio margen discrecional para que las empresas de transporte de mercancías determinen sus condiciones específicas de operación; a partir de lo cual se utiliza una modalidad en la que el recojo, traslado y entrega de los bienes -incluyendo el producto minero- se 


\section{Vanessa Sofía Valverde Luna y Diego Alonso Collantes Añaños}

realiza en bolsas cerradas y precintadas, por lo que no se comprueba su contenido más allá de lo declarado por el remitente. Estimamos, por consiguiente, necesario modificar el artículo 45 de dicho reglamento para incorporar dentro de las condiciones del servicio de transporte, la exigencia de requerir al remitente documentación mínima sobre el origen lícito de la mercancía, especialmente cuando se trate de mineral aurífero.

La verificación de la documentación que le es exigida al adquirente de oro se realiza a través de fuentes de información pública como el Registro Nacional de Declaraciones de Compromisos (hoy Registro de Saneamiento), el Registro de Comercializadores de Oro, y las páginas web de la SUNAT y SUNARP; las cuales son muchas veces insuficientes para conocer con razonable certeza el auténtico origen del mineral, habida cuenta de la práctica de los vendedores de consignar información falsa. Por ello, consideramos que la creación de una entidad encargada de la certificación mínima del origen del mineral es una opción que podría dar mejores resultados.

Finalmente, si bien el Estado ha ido adecuando, en los últimos años, el proceso de formalización de la pequeña minería y minería artesanal con el fin de simplificar los procedimientos, lo cierto es que las cifras demuestran que el proceso de formalización aún no es suficientemente atractivo para la gran mayoría de mineros informales, por lo que es necesario un estudio que combine el conocimiento normativo sobre la materia, con trabajo de campo que recoja y sintetice los puntos de vista de los regulados.

\section{Referencias bibliográficas}

Alvarez-Berríos, Nora y Mitchell Aide. 2015. Global demand for gold is another threat for tropical forests. Environmental Research Letters 10 (enero). https://doi:10.1088/17489326/10/2/029501

Arbulú Ramírez, José. 2014. Lavado de activos - prevención, detección y control. Lima: Ediciones Legales.

Baldwin, Robert, Martin Cave y Martin Lodge. 2012. Understanding Regulation - Theory, Strategy, and Practice. New York: Oxford University Press.

Calle, Isabel y Lenin Valencia. Diez recomendaciones de la SPDA respecto a los nuevos decretos sobre minería informal e ilegal. En Sociedad Peruana de Derecho Ambiental. Actualidad Ambiental http://www.actualidadambiental.pe/?p=42753 (consultada el 12 de noviembre de 2017).

Caro Coria, Dino Carlos. 2016. Criminalidad Organizada en Materia Ambiental: a propósito del delito de Minería llegal. En Ley contra el Crimen Organizado (Ley No. 30077), Aspectos sustantivos, procesales y de ejecución penal. Instituto Pacífico, Lima.

García Cavero, Percy. 2007. Derecho Penal Económico, Parte General, Tomo I, 2da edición. Lima: Editorial Jurídica Grijley.

García Cavero, Percy. 2013. El delito de lavado de activos. Lima: Jurista Editores.

García Delgado, Francesca. Los nuevos decretos legislativos contra la minería ilegal. En Diario El Comercio. https://elcomercio.pe/lima/nuevosdecretos-legislativos-mineria-informal-159109 (Consulta: 12 de noviembre de 2017).

Dargent, Eduardo et al, ed. 2017. "Cycle of abundance and Institutional Pathways". En Resource Booms and Institutional Pathways, 1-40. Switzerland: Palgrave Macmillan.

Habermas, Jürgen. 2001. El valle de lágrimas de la globalización. Claves de razón práctica 109 (enero/febrero): 4-11.

Huamán Castellares, Daniel. 2016. El delito de minería ilegal: principales aspectos sustantivos sobre el tipo base y sus agravantes. En Hurtado, José, dir., Temas de Derecho Penal Económico: Empresa y Compliance - Anuario de Derecho Penal. Lima: Pontificia Universidad Católica del Perú, 423-446.

Ministerio de Justicia y Derechos Humanos. 2017. Trata de personas en el Perú - Criminología de actores y perfiles penitenciarios. Lima: Ministerio de Justicia y 


\section{Alcances para una respuesta jurídica integral al comercio ilegal de oro Approaches for a comprehensive regulatory response to illegal gold commerce}

Derechos Humanos; Capital Humano y Social Alternativo CHS.

Macroconsult. 2012. Impacto Económico de la Minería en el Perú. Lima: Sociedad Nacional de Minería, Petróleo y Energía.

Mujica, Jaris. 2014. Elementos comparados del impacto de la trata de personas en la salud de las víctimas adolescentes en el contexto de la minería ilegal de oro en Madre de Dios. Lima: Centro de Promoción y Defensa de los Derechos Sexuales y Reproductivos (PROMSEX).

PODER. "La minería ilegal ya genera más 'dinero sucio' que el narcotráfico", mayo 2015. https://poder.pe/2015/05/26/00242-la-mineriailegal-ya-genera-mas-dinero-sucio-que-elnarcotrafico/ (consultada el 11 de noviembre de 2017).

RPP Noticias. ¿Quién es "Peter Ferrari” y por qué fue detenido por la policía? http://rpp.pe/ lima/actualidad/quien-es-peter-ferrari-y-por-que-fue-detenidopor-la-policia-noticia-1021015 (consultada el 13 de noviembre de 2017).

Prado Saldarriaga, Víctor. 2013. Criminalidad Organizada y Lavado de Activos. Lima: Idemsa.

Shafiee, Shahriar y Erkan Topal. 2010. An overview of global gold market and gold price forecasting. Resources Policy 35 (septiembre): 178-89. https://doi.org/10.1016/j. resourpol.2010.05.004

Salo, Matti et al. 2016. Local perspectives on the formalization of artisanal and small-scale mining in the Madre de Dios gold fields, Peru. The Extractive Industries and Society 4 (noviembre): 1058-66. https://doi.org/10.1016/j.exis.2016.10.001

Silva Sánchez, Jesús María. 2011. La Expansión del Derecho Penal, $3^{\mathrm{a}}$ ed. Madrid: Edisofer.

Sociedad Peruana de Derecho Ambiental. 2015. Las rutas del oro ilegal estudios de caso en cinco países amazónicos. Lima: Sociedad Peruana de Derecho Ambiental. 